Essay

\title{
Climate Change and Food In/Security: A Critical Nexus
}

\author{
Md Saidul Islam * and Andrea Ting Wong \\ Division of Sociology, Nanyang Technological University Singapore, 14 Nanyang Drive, \\ Singapore 637332, Singapore; AWONG004@e.ntu.edu.sg \\ * Correspondence: msaidul@ntu.edu.sg \\ Academic Editors: Jason K. Levy and Peiyong Yu \\ Received: 22 February 2017; Accepted: 16 May 2017; Published: 19 May 2017
}

\begin{abstract}
The issue of climate change has been gaining widespread attention and concern as it has the ability to directly/indirectly affect our standard of living and quality of life. It has often been postulated that changes in climate would have a vast effect on food production systems and that food security might be threatened due to increasing climate change. However, it seems that research on climate change and food in/security has often been one-sided; with climate change being identified as the cause of food insecurity and not how the systems in place to ensure food security have exacerbated the issue of climate change. This paper thus seeks to give a more balanced view and thus understanding of the complex relationship between climate change and food security by critically examining both systems.
\end{abstract}

Keywords: climate change; food security; soil; water; food availability

\section{Introduction}

Climate change has always been a prevalent phenomenon. However, it is only in recent years that this issue has been given attention by international bodies, non-profit organizations, national bodies, corporations and individuals. As warned by the 44th President of the United States of America, Mr. Barrack Obama, climate change is no longer a problem of the future but rather a challenge that "will define the contours of this century more dramatically than any other" [1]. Climate change is defined as:

"The change in the state of the climate that can be identified (e.g., using statistical tests) by changes in the mean and/or variability of its properties, and that persists for an extended period of time, typically decades or longer. It refers to any change in climate over time, whether due to variability or as a result of human activity."-[2]

Climate change has not only resulted in increasing global-averaged mean annual air temperatures but also the increased amount of atmospheric greenhouse gases (GHGs) [3]. It has been reported that the global mean temperature has increased by 0.74 degree Celsius during the last 100 years and that the Gangtori glacier, one of the Himalayas' largest glaciers, is rapidly disintegrating at $12-13 \mathrm{~m}$ a year $[3,4]$. The impacts of climate change such as the depletion of water resources and the rise in average global temperature have created conditions for a decline in agricultural production. This in turn leads to escalated food inflation globally as well as food shortages in the developing countries where the poor suffer greatly as they are unable to pay the upmarket prices for food [3].

According to the Food and Agricultural Organization of the United Nations (FAO), there are about 795 million people who are undernourished globally, with poor nutrition accounting for nearly $45 \%$ of deaths in children below the age of 5 annually. A further $13.5 \%$ of the population in developing 
countries are undernourished due to the lack of food availability; stability of food; and/or economic and physical access to food [5]. These findings are expected to be further exacerbated due to the rise in world population, projected by the United Nations to increase by 2.4 billion by 2050 [6]. The rise in population coupled with growing urbanization and increasing environmental problems such as pollution and deforestation, would have detrimental effects on food production, distribution and consumption. In addition, the inability of food producers to meet the demands of the population would cause food prices to escalate. This, together with the increased occurrences of climate-related disasters and further climate changes worldwide, would worsen the problem of food security faced by the already-at-risk individuals / populations as well as the global community. Food security is thus understood as:

"A situation that exists when all people, at all times, have physical, social and economic access to sufficient, safe and nutritious food that meets their dietary needs and food preferences for an active and healthy life."-[7]

In addition, with the recent signing of the climate agreement introduced in the Paris Climate Conference (COP 21) that seeks to limit global temperature rise to well below two degrees Celsius, more attention has been turned towards greening movements and alternative forms of actions to reduce their greenhouse emissions [8]. There has been a rise in alternative forms of eco-friendly food production processes such as the System of Rice Intensification (SRI), that can substantially reduce GHG emissions as compared to conventional forms of agriculture [9]. However, despite such alternative forms of food production, the FAO reported in 2014 that GHG emissions from agriculture, forestry and fisheries have almost doubled over the past 50 years. This figure is expected to increase by an additional $30 \%$ by 2050 if nothing is done to reduce it [10]. Thus, it can be seen that more knowledge and understanding of the effects of conventional procedures is needed before switching to alternative forms of sustainable and eco-friendly processes, so as to ensure that the changes lead to positive and meaningful outcomes.

Since the primary purpose and commonality between agriculture, fisheries and forestry is food production to achieve food security, this essay will thus focus on understanding the dialectic relationship between climate change and food security: precisely how climate change impacts food security and how food production impacts climate change. Upon establishing the link between the three factors (soil, water, and crops), a clearer picture and understanding of what needs to be done so as to achieve food security amidst climate changes will emerge. Though there are many ways to examine climate change, this paper would pay close attention to anthropogenic drivers of climate change.

\section{Materials and Methods}

This paper utilizes various qualitative approaches in understanding the relationship between climate change and food in/security. In order to gain a better insight of food production systems, climate change and food security, we have chosen to use both content and discourse analysis in order to gather the information needed for this research. These unobtrusive forms of methodology enabled us to sieve out helpful information that would have been otherwise obstructed by geographical restrictions, through the analyzing of a wide database of research papers and books on the topics of climate change, food production systems and food security.

Content analysis - a robust examination of relevant materials—was utilized for capturing and observing trends or patterns found in climate change, food production systems and food security. Through the employment of content analysis, various variables proposed by scholarly and academic journals as responsible or related to climate change and food in/security were also identified. Besides peer-reviewed credible sources, we also consulted and juxtaposed our analysis with other soft sources such as newspaper and Internet reports. In our examination, we analyzed the various findings in academic journals and research papers. This analysis helped to sieve out relevant information of climate change and food in/security through the use of reasoning and analytical thinking. Along with 
content analysis, discourse analysis was also utilized for studying text linguistics, i.e., tone, phonology, syntax, style and organization, in academic research papers. Through the deconstruction of texts, implicit or hidden contents in academic research papers were made more obvious, thereby helping in one's understanding of climate change and food in/security. A combination of both content and discourse analysis was necessary to capture the complex dynamics and critical nexus between food in/security and climate change.

\section{Research Findings}

\subsection{How Climate Change is Affecting Food Security}

Although there are many factors affecting climate change, the main factor often flagged as the cause for worsening climate conditions is the increase of greenhouse gas emissions in the atmosphere. The increased concentration of GHGs in the atmosphere is expected to trap more heat on Earth which in turn results in an increase in global mean temperatures [11]. Climate change causes adverse impacts on both ecosystems and human societies as it increases the incidence of floods, droughts and other climate-related disasters that have the potential to affect farmlands, livestock and animal husbandry, which are essential for agricultural purposes [12]. In order to better understand the effects of climate change on food security, this paper will focus on three factors identified to have the most direct effects on food production: soil, water and crops [13]. These three factors are crucial in understanding the effects that climate change has on food security as they are the most basic and essential components of food production.

\subsubsection{Soil}

Soil resources are limited, unequally distributed and susceptible to degradation by land misuse, mismanagement and climate change [13]. Climate change, i.e., high atmospheric carbon dioxide concentrations $(\geq 400 \mathrm{ppm})$, along with increasing air temperatures $\left(2-4{ }^{\circ} \mathrm{C}\right.$ or greater) that persist for an extended period of time, will significantly affect soil properties and fertility, food quantity and quality, and environmental quality [14]. This is because the atmospheric Carbon (C) Cycle is dynamic and responsive to climate change [13]. In addition, accelerated weathering of the rocks and minerals in soils are exacerbated by high atmospheric $\mathrm{CO}_{2}$ concentrations ( $\left.\geq 400 \mathrm{ppm}\right)$, temperatures, intensive rainfalls, heat waves and extended periods of drought [14].

Although weathering has the ability to decrease carbon dioxide concentration (through increasing the inorganic carbon (IC) pool in soils via carbonate mineral formation), it can also disturb the balance between biotic and abiotic C cycles within soils [14]. This disturbance affects the distribution of C into "less stable soil pools; increasing containment mobilization that might significantly alter soil microbial activity, plant productivity, life in soils, and C and elemental cycling ... [as well as] the elemental balances in rivers, lakes and oceans" ([14], p. 117). Changes in the carbon dioxide concentration in soil affects the organic matter content of soils and soil quality, resulting in soil degradation. Soil degradation reduces the output of agriculture and the efficiency of inputs. In addition, this decline in soil quality might increase land's vulnerability to degradation including "crusting, compaction, accelerated erosion and salinization" ([13], p. 10). Climate change thus leads to soil-related consequences that include "significant/dramatic changes in soil properties, surface water and groundwater quality, food (national) security, water supplies, human health, energy, agriculture, forests, and ecosystems" ([14], p. 114).

In addition, research has also shown that climate change causes adverse impacts on humanity and agro-ecosystems and thus food security, as it increases the likelihood of climate-related disasters such as droughts, floods and heatwaves [15]. This affects the drying-rewetting cycles of the land, which in turn, directly affects the "microbial nitrogen $(\mathrm{N})$ turnover rates in soil by changing the water content and the oxygen partial pressure" ([16], p. 1). These changes might increase the likelihood of nitrification that will lead to nitrate formation, and depending on the soil type, nitrates might enter groundwater streams and significantly reduce the availability of $\mathrm{N}$ pools in soil [16]. The impoverished 
soil in turn affects food security as it causes a reduction in quality and quantity of crops, thereby lowering the availability of food for the population. Changes in the $\mathrm{N}$ content in the soil have the potential to affect soil nutrient levels that get taken up by plants, and this can result in yields having low tissue concentrations of trace elements [17]. This can, in turn, lead populations that rely solely on such crops for nutrients to suffer from micronutrient deficiencies as they lack alternative dietary choices to compensate for the lack of nutrient intake from these crops.

Research has shown that damage to soil is irreversible when beyond a certain threshold, as it is a non-renewable resource. Damaged soil might thus be a more imminent and immediate problem to society than the depletion of fossil fuels, as it not only affects food production but also the emission of greenhouse gases and the quality and quantity of water [18]. This is because the three systems i.e., land, water and atmospheric conditions, are interconnected and integrated. Thus, it is clear that the soil factor plays a vital role in ensuring food security. However, climate change has also altered the carbon concentration and the nutrients present in soil and this has in turn affected crop production (i.e., quality and quantity), water resources and hence food security.

\subsubsection{Water}

Similar to soil resources, water resources are also scarce and susceptible to pollution, contamination, eutrophication and changes in climate [13]. It has been reported by the United Nations Department of Economic and Social Affairs (UNDESA) in 2014 that existing climate change scenarios would result in almost half the world's population living in areas of high water stress by 2030 [19]. The changing precipitation is altering the hydrological systems, affecting water quality and quantity [13]. Water availability is being threatened by climate change as it has the potential to decrease or cause fluctuations in temperature and precipitation in some regions of the world [20]. Fluctuations in rainfall and temperature can potentially cause crop failure especially for crops that require high temperature and rainfall conditions, e.g., rice.

As mentioned earlier, climate change affects the drying-rewetting cycles of the land, thereby changing the $\mathrm{N}$ content in soils. This in turn affects water resources when nitrates from the soil seep into groundwater systems and alter the nutrient concentration of water bodies. The increased $\mathrm{N}$ concentration in water bodies may lead to the process of eutrophication. Eutrophication is a process whereby nutrient overloads in the water body lead to an increase in floating plant communities and plankton [21]. In addition, increased production of floating plant communities is also facilitated by warmer water bodies, due to climate change, that encourages and prolongs the growing period. The increased growth in floating plant communities will have an adverse effect on submerged plant communities, as sunlight needed for these plants to photosynthesize is being blocked and absorbed by the plants floating on the surface. In order to grow, these floating plant communities compete with submerged plants and other marine animals for nutrients present in the water bodies.

The inability of submerged plant communities to photosynthesize, respire and absorb the necessary nutrients might eventually lead to the death of these plants. The deaths of submerged plant communities will alter the chemical balance in water bodies due to the increase in oxygen content in water bodies, as plants are no longer able to take in oxygen and convert it to carbon dioxide via the process of respiration. This in turn upsets the aquatic biodiversity as marine animals reliant on these plants for food are also affected by changes in the food chain. Animals which are not able to switch to alternative forms of food might either die or have nutritional deficiencies due to changes in nutrition uptake. Thus, increased nitrogen content in water bodies and warmer water conditions have led to the increase in floating plant communities at the expense of submerged aquatic plant diversity.

In addition, the high concentration of GHGs in the atmosphere together with the irresponsible disposal of chemicals into water bodies has altered water concentration, leading to ocean acidification and hypoxia that will influence the distribution and productivity of fisheries and aquaculture in many places [22]. The rising global temperature has also led to the rise in the temperature of water bodies, and marine animals that are unable to acclimatize or migrate to cooler water bodies will thus be 
affected. Studies have indicated that even a small rise of $1{ }^{\circ} \mathrm{C}$ in water temperature could greatly impact the mortality of fishes, breeding, geographical distributions, and harvests [23].

It has also been postulated that rising temperatures in water bodies have led to smaller body sizes of fishes such as herring and haddock [24]. This is because warmer water conditions have increased the anabolic oxygen demand underwater while simultaneously reducing oxygen solubility necessary for survival [24]. Thus, in order to adapt to the change in oxygen content underwater, fish species have evolved to have smaller bodies so that they have a larger surface area to volume ratio to balance their oxygen demand and uptake [24]. This biological change in fishes is worrying as it not only represents a decrease in per-capita reproductive rates and decreased resilience against predators and altered ecosystems, it also threatens food security [24]. With reduced per-capita reproductive rates, the fish species population will be significantly reduced. Warmer water conditions thus threaten food security, as these warmer conditions result in the reduction of food availability and stability-decreased fish species populations and smaller body-sized fishes.

In addition, rising global temperatures have also resulted in water bodies drying up, leading to the phenomenon of desertification. Desertification causes the loss of arable land as the lack of water causes the land to harden and make it unsuitable for crop production or livestock rearing. Clearly, climate change has a significant influence over water as it not only alters the physical conditions (e.g., temperature and land conditions) and chemical environment (e.g., acidity and oxygen content) in water bodies but also changes the biological environment, i.e., the decline in aquatic life and the shift in marine species distribution and abundance [25]. These changes will in turn reduce agricultural output and this, coupled with growing world population, food supply demands and consistent or worsening climatic conditions, will in turn result in detrimental impacts on food security.

\subsubsection{Crops}

Climate change has also increased the frequency of climate-related disasters such as floods and droughts. Both have direct adverse impacts on crop production and food security. Global temperature rise has resulted in floods due to increasing sea levels caused by the melting of glaciers and the expansion of oceans [26]. Sea-level rise (SLR) affects food security and food production as the rise in sea level can lead to increased flooding and saltwater intrusion into soil, groundwater and freshwater bodies [26]. SLR can result in crop failure when the crops become submerged by the floodwaters that prevent aeration of the soil. Saltwater intrusion can also result in salinization and water-logging which causes land degradation, thereby making affected land unsuitable for the cultivation of crops. It has been discovered that an SLR of $1.5 \mathrm{~m}$ in Bangladesh may flood about $16 \%$ of the country's land area and make it unsuitable for rice production [26]. Droughts, many of which are caused by climate change, can result in crop failure as the lack of water available for agricultural production causes crops to die. This is evident in the significant drop in crop yields, i.e., maize yields in Italy and France dropped $36 \%$ and 30\% respectively, during the severe heat season in Europe in 2003 ([27], p. 225). Droughts also affect soil quality, as they can lead to a decline in plant-available water capacity, making the land unsuitable for crop production.

In addition, the rise in global temperatures caused by climate change might result in an increase in the growth of weeds and consequent use of pesticides [28]. With rising temperatures, crops are faced with more intense attacks from pests and are more susceptible to diseases that threaten to wipe out the harvest [29]. This is because rising temperatures generally create more optimal conditions for disease-causing organisms and pests, which will have adverse effects on crop growth, as these factors affect the quality and quantity of crops [29]. It has been postulated by researchers from the Indian Agricultural Research Institute that there would be a "loss of 4-5 million tonnes in wheat production with every $1{ }^{\circ} \mathrm{C}$ rise in temperature throughout the growing period" ([23], p. 219). Climate change thus affects food security, as increasing temperatures and conditions detrimental to crop production affect the quality and quantity of crops. 
Another effect of climate change affecting crop production is change in atmospheric conditions such as the rise in GHGs-rising carbon dioxide levels. It has been postulated that carbon dioxide concentrations will rise from current atmospheric levels of about $385 \mathrm{ppm}$ to about $500-1000 \mathrm{ppm}$ by 2100 [30]. Elevated levels of atmospheric carbon dioxide are said by some to be beneficial to the physiology, growth and chemistry of the plant. It has been postulated that "a twofold increase in $\mathrm{CO}_{2}$ will lead to a $10-15 \%$ increase in dry matter production provided that all other factors remain constant ([29], p. 363). This is because increased carbon dioxide allows for an increased rate of photosynthesis, thus allowing for an increased production of products (e.g., water, glucose and oxygen). However, it is important to note that the benefits of increased carbon dioxide levels, as mentioned earlier, are only possible if they are independent of any effects of climate change, i.e., rising global temperature and changes to nitrogen content in soil. Researchers at Stanford University have discovered that elevated concentrations of carbon dioxide in the presence of other effects of climate change will instead lead to a reduction in plant growth and nutrients [31].

Nitrogen changes in soil coupled with increased atmospheric carbon dioxide have the effect of making changes in plant tissue nitrogen and this can in turn affect the protein concentrations of plants. There is a lack of surface area for crops to take up other nutrients and minerals, as elevated levels of carbon dioxide encourage higher levels of photosynthetic activity that leads to the formation of more nonstructural carbohydrates. This in turn takes up the space needed for the uptake of other minerals and nutrients such as calcium, magnesium, nitrogen and phosphorous [30].

Furthermore, rising global temperatures can cause heat injury and physiological disorders in crops, thus affecting the quality and quantity of crops produced [29]. Climate change consequences affect carbon dioxide levels, as seen with the increased nitrogen concentrations in soils and rising global temperatures. It is evident that the effects of rising carbon dioxide levels are in fact detrimental to crop production. Crops are also adversely affected by climate change due to the altered weather conditions and seasons (due to increased global mean temperature) required to grow specific crops, e.g., growing of rice during the monsoon period. However, there are two sides of the effects of climate change on crop production. First, climate change can reduce the growing period of crops thereby allowing for more production cycles which in turn increases production output [20]. Climate change can also reduce crop rotation period and enable more crops to be produced in a year. However, one of the downsides of climate change on crop production is that though there may be increased output due to reduced crop rotation periods, the increase in output might not be from crops that are of greater demand. This is because some crops, especially rice, a source of staple in most Asian countries, requires specific growing conditions.

\subsubsection{How all Three Factors Affect Food Security}

The impact of soil, water and crops on food security will be measured using four components: food availability, economic and physical access to food, food utilization and the stability of food supply. Food availability refers to the physical presence of food available for consumption; economic and physical access to food refers to having the ability/resources to acquire food; food utilization refers to having the "appropriate nutritional content of food and the ability of the body to use it effectively"; and stability of food supply refers to the ability to ensure that there is sufficient food for individuals all the time ([32], p. 14).

\section{Food Availability}

If the soil lacks nutrients or is unable to support the growth of crops, there would be a lack of supply of crops and hence the availability of them. Likewise, if the water is contaminated due to its high acidic concentration, crops would die as the acidity of the water would kill the crops. In addition, the rise of natural disasters such as floods and droughts affect food security, as drought prevents the growing of crops and leads to crop failure or the delay of crop production, while floods cause crops to die or the land to be unsuitable for agricultural purposes due to the lack of fertile soil. Crops 
are sensitive to changes in temperature and precipitation, and a rise in global mean temperatures by $2{ }^{\circ} \mathrm{C}$ can destabilize agricultural practices and crop production periods [20]. In addition, food availability is further threatened as climate change leading to climate fluctuations has the potential to lead to the loss of local diversity and translate to lower variety of resources for both current and future generations [33].

As mentioned earlier, climate change has the potential to alter the geographical distribution of some marine animals such as oil sardines, due to increased temperatures in water bodies that make the water conditions unsuitable for their continual survival. This migration can increase the number of fisheries in those areas and thus increase employment opportunities as well as food. Some might view the migration of fishes to other regions in a positive light as it would increase food availability and physical access to food in those regions. However, the original habitats from which these fishes originate would be greatly affected. Fisheries and local fishermen would notice a substantial drop in catch as fishes that are unable to adapt to changing water conditions shift to other water bodies. The drop in catch would thus result in a decrease in food availability, employment and a rise in prices due to the drop in supply. This would in turn affect food security as now these places would have reduced access and availability of food.

\section{Economic and Physical Access to Food}

When crops fail due to climate-related disasters, farmers are unable to sell their crops to earn money to support their families. Between 2003 and 2013, these disasters affected more than 1.9 billion people in developing countries and resulted in about half a trillion US dollars in estimated damages [5]. FAO estimates that the "agricultural sector absorbs approximately 22 percent of the total economic impact of these disasters" which in turn affects its capability to support food security [34]. Evidently the effects of climate change are unequal. The poor (developing countries) are more affected by climate change and crop failure, being mainly agricultural economies, as compared to the rich (developed countries), as poor countries lack the knowledge and skills to deal with such changes, i.e., the ability to stockpile sufficient food for their people when crises strike.

In addition, farmers in developing countries often live from one harvest to another, and thus the failure of one harvest might cause them to lose all their savings. As such, they no longer have the financial means to buy food or obtain food from their harvest. This is especially so in developing countries where the governmental supports for farmers are not as strong as those in developed countries. Thus, when crops fail, these farmers are often left without a safety net to recoup from their losses or the ability to provide food for their family. It is postulated that with increased climate change, rice production in the Philippines might decrease as much as 75\% by 2100 [35]. This decline might result in many Filipinos having to settle for meals with little or no rice due to the rice shortage as well as the lack of economic access to food. This problem can however be lessened if the government intervenes and implements climate adaptation programs, i.e., increased use of technology for agricultural purposes, to help prevent such significant losses in rice production [35].

Climate change might increase the frequency and intensity of climate-related disasters that can further exacerbate the existing problems that climate change has brought upon food security as it further disrupts crop production, livestock rearing and trade. This might in turn result in premium prices for food, thus worsening the problem of food insecurity. Climate-related disasters might also cause infrastructural damages, thus trapping individuals in areas where they have limited or no physical access to food. In addition to this scenario, natural disasters might create conditions that prevent the transportation of food from producers to customers. The inability of food exports to reach their final destinations might lead to food shortages in such communities, thereby leading to food insecurity. 


\section{Food Utilization}

Climate change affects the variety of foods with higher nutritional value that are available for people, due to disruptions in trade and crop production. As indicated earlier in Section 3.1.1, climate change can alter the nutritional value in the crops produced as it changes the nutrient levels in soil. Individuals whose main diet consists of crops produced under impoverished soil conditions are susceptible to malnutrition and nutrient deficiencies due to decreased nutrient content in the foods they are consuming. Therefore, the full nutritional value of food cannot be fully absorbed if climate change causes changes in food production factors, i.e., soil and water, that decrease the nutritional value found in food yields. Food utilization is thus negatively affected, as nutritional content of food is insufficient for the body to use it effectively to meet the dietary needs for a healthy lifestyle $[16,17]$.

In addition, climate change might affect the safety of the food, as the use of contaminated water to grow crops might indirectly cause consumers to consume toxic products. Climate-related disasters such as flooding might also cause harmful substances to enter water sources such as wells, thus polluting water sources that are used for hydration and agricultural purposes. Flooding might also lead to large pools of stagnant water in communities that can increase the chances of vector-borne (e.g., malaria and dengue) and water-borne (e.g., cholera) diseases that affect the health of individuals and their ability to utilize food properly [36].

In times of climate-related disasters, people might not have the luxury to pick foods that are rich in nutrients due to the shortage in food availability. Instead, they might turn to rationing consumption to prioritize calorie-rich but nutrient-poor foods, which will lead to a decrease in dietary quality, resulting in the loss of health, productivity capacity and low incomes [22]. Thus, food security is threatened, as food cannot be utilized as effectively due to the decline in nutritional value of food and food safety.

\section{Stability of Food Supply}

Climate change affects the stability of food due to changing anthropogenic conditions, drying-rewetting cycles and global mean temperatures, that would affect livestock rearing and crop productions. Some governments and farmers have turned to technological advances and developments in hopes of reducing the effects of climate change on food stability. However, there is a possibility that technological advances used to mitigate the effects of climate change might further exacerbate the issue of food security and climate change.

Climate change is a complex matter and the full extent of its effects is still being unraveled today. It remains to be seen if the technological advancements incorporated into food production systems will indeed lead to reduced climate change effects and increased food stability, as many of these advances are still in their infancy period. More research and time is thus needed to gain a better understanding of these advances.

Stability of food supply is not only affected by climate change but also by other factors such as food distribution and transportation. It has often been reported that climate change increases the frequency and intensity of climate-related disasters, and this in turn affects the stability of food supply as food trade is hindered when planes and ships are grounded/docked due to poor visibility as a result of harsh weather conditions or access roads that are destroyed by earthquakes or flooding.

Instability of food supply is felt mostly in developing countries that do not practice stock-piling. Often, these countries lack the technical expertise and financial resources to bring in experts and engineers to help build infrastructures that can withstand the impact of natural disasters, and storage conditions that allow for food to be stored for an extended period of time. Stability of food supply is thus affected when major infrastructure and transportation hubs such as airports/ports are closed or food storage buildings collapse during such disasters. In addition, developing countries lack the monetary funds and technological advancements necessary to help mitigate crises such as the acidification of oceans and salinization of the soil, to ensure constant production and supply of food for their people. 
Therefore, based on the components of food security-food availability, economic and physical access, utilization and the stability of food, it is obvious that climate change has both a direct and indirect impact on food security. The inability of people to get their hands on nutritious food to meet their dietary needs and food preferences for an active and healthy life goes against the very definition of food security. The examples given have shown the current and future challenges that climate change will bring to agricultural and livestock-rearing methods that are used to meet the food demands of the population.

Numerous research studies on the effects of climate change on food production have led to many governments or farmers incorporating various adaptation methods to their agricultural practices so as to reduce the effects of climate change on yields. However, many researchers fail to see that there is a connection between food production systems and climate change, e.g., "rice farming is responsible for approximately $10 \%$ of the methane released" into the atmosphere ([35], p. 189). In order to gain a better understanding of the issue of food in/security, it is essential that both systems be examined without prejudice. As such, this paper would now examine the impact of food production systems on climate change in hopes of providing a more balanced view of the issues of food in/security and a greater understanding of the issue of climate change and food in/security.

Food production systems would be examined instead of the components of food security as the latter is the by-product of the former. Without food production systems, there would not be a concept of food security as there would be no production of food to allow all people, at all times, to have physical, social and economic access to sufficient, safe and nutritious food [7].

\subsection{How Food Production Systems Are Affecting Climate Change}

The world's population in 1990 was 5.3 billion people, and over the span of 15 years this figure increased by 2 billion [37]. The projected population growth for 2050 is said to be 9.4 billion according to a report released by the U.S. Census Bureau in 2015. In order to keep up with the growing population, it is necessary that food production be increased manifold. There are many components of food production systems, however, for the purposes of this paper, food production will be defined as the system which encompasses the growing, processing, distribution and consumption of food products.

The increased demand for agricultural produce has led to many food producers turning to artificial means such as the use of fertilizers (e.g., the input of inorganic and organic nitrogen in agro-ecosystems) to increase soil fertility for crop cultivation and hence increased harvests, instead of waiting for the land to rest and fallow between crop rotation and harvests. According to studies, agriculture sectors have been identified as being responsible for $13.5 \%$ of the global GHG emissions, and one factor apart from deforestation that plays a significant role in these relatively high GHG emissions in the atmosphere is the excessive use of synthetic fertilizers, pesticides and insecticides [18]. Though the use of fertilizers, pesticides and insecticides has reduced the amount of crops being lost to pests and diseases and increased the overall yield of crops, the mismanagement and misuse of these synthetic means to achieve food security can instead reduce the efficiency of plants to take up nitrogen. This in turn leads to an increase in $\mathrm{N}_{2} \mathrm{O}$ (and NOx) emissions in the atmosphere [38].

The use of $\mathrm{N}$ fertilizer for agricultural purposes has led to "emissions of $\mathrm{N} 2 \mathrm{O}$ from food systems account[ing] for 77\% of total anthropogenic emissions" ([38], p. 474). In addition, the production of nitrogen fertilizers leads to the release of GHGs such as methane, carbon dioxide and nitrous oxide, thus increasing the concentration and percent of GHGs in the atmosphere [39]. $\mathrm{N}_{2} \mathrm{O}$ exacerbates climate problems as it depletes the stratospheric ozone, increases anthropogenic discharges into the atmosphere and causes global mean temperature to increase [38]. In addition, changes in global mean temperatures lead to rising sea levels due to the melting of polar caps and alteration of weather cycles, which might result in climate-related disasters such as flooding.

In addition, in order to increase the amount of food to meet the ever-growing demands of the world's 7.3 billion people, large conglomerates have been buying out small, family-owned agricultural businesses to convert them into huge food production enterprises. This results in large amounts of 
forest area being deforested to increase arable land for crop production and livestock rearing. As of 2012, cattle ranchers, loggers and soya farmers had stripped $17 \%$ of the Amazon forests in Brazil, and at the peak of clearance, 10,723 square miles were deforested in a year [40].

The effects of deforestation have a huge impact on climate change. Trees are natural air purifiers of the Earth- a tree takes in carbon dioxide for photosynthesis and releases oxygen back into the atmosphere; it also stores carbon within its leaves, thereby reducing the carbon concentration in the environment that contributes to GHGs. In addition, a tree's transpiration and canopy reduces temperature, as it affects "radiation absorption and heat storage, wind speed, relative humidity, turbulence" [41]. Thus, when trees are cleared to increase food production, the Earth loses its natural air-purifiers and natural air-conditioners, which results in large amounts of carbon dioxide being released into the atmosphere. This increases the GHG concentrations exponentially, which exacerbates climate problems, i.e., the rise in global mean temperatures.

Deforestation also increases the likelihood of salinization, soil erosion, acidification and desertification as it alters the natural landscape and the normal functionalities of the systems, e.g., deforestation removes tree roots that would otherwise hold the soil together and prevent it from being washed away during heavy rainfall. In addition, when topsoil is washed away, the nutrients and minerals that make the soil fertile for cultivation are also removed.

The introduction of synthetic means of increasing soil fertility and productivity through the use of fertilizers with high levels of inorganic or organic $\mathrm{N}$ might alter chemical compositions in water bodies as these fertilizers are washed into rivers and lakes. The introduction of these natural and artificial nutrients and minerals can lead to water pollution (i.e., acidification and eutrophication) and the death of aqua flora and fauna that are unable to adapt to this change.

Studies have also shown that the effects of deforestation (e.g., salinization, acidification, desertification, and soil erosion) and the excessive use of artificial fertilizers have rendered once productive arable crop land into infertile, unusable land [42]. Thus, it can be seen that food production systems, the effects of climate change and food security are all closely linked and integrated, as changes to one system can lead to substantial effects on the other systems.

In addition, other than clearing land for food processing and distribution purposes, food production systems are also heavily dependent on fossil fuels for transportation, creation of artificial fertilizers and pesticides and the running of various machineries needed for packaging, producing and distributing food [42]. It has been discovered that the production of nitrogen fertilizers uses large amounts of fossil fuels such as coal that "can account for more than 50 per cent of total energy use in commercial agriculture" and 1.2\% of all anthropogenic GHG emissions [43]. A life-cycle study in the United States of America found that "agricultural transport as a whole contributes $11 \%$ of all agricultural GHG emissions from agriculture" ([44], p. 5). However, the actual contribution of agricultural transport emissions is higher than the stated figure as it fails to include emissions from agricultural inputs.

Agriculture is reliant on transportation, as food needs to be exported or imported to areas where consumers can have access to it. The total distance food travels from the original production site to its place of consumption is termed as 'food miles' [44]. For most cases, higher food miles would equate to greater GHG emissions as more fossil fuels are required to be combusted for transportation purposes. Thus, food supplies that are transported overseas via air freight often account for a high amount of GHG emissions. The estimates of the various forms of transportation are as follows: air transport contributes $1.093 \mathrm{CO}_{2}$ equivalent $/ \mathrm{t} / \mathrm{km}$, truck transport contributes $0.15 \mathrm{CO}_{2}$ equivalent $/ \mathrm{t} / \mathrm{km}$ and rail transport at $0.01 \mathrm{CO}_{2}$ equivalent $/ \mathrm{t} / \mathrm{km}$ [44].

In the World Urbanization Prospects: The 2014 Revision published by the UNDESA [45], it was reported that $54 \%$ of the world is now urbanized. This means that there is less land available for agricultural purposes or that more land needs to be cleared in order to meet the agricultural demands of the ever-growing population. Countries like Singapore which lack land area for food production are thus reliant on other countries for food import. Singapore imports more than $90 \%$ of their food, e.g., 
$73 \%$ of eggs are imported from Malaysia, and $63 \%$ of frozen chickens are imported, of which $84 \%$ are imported from Brazil [46]. The importing of food contributes to climate change as transportation of food from one place to another requires energy that is usually generated by the burning of fossil fuels. With rising world population and an approximation of two-thirds of the world being urbanized by 2050 , the carbon footprint associated with the transportation of food will certainly increase from the current rate of $11 \%[45,47]$.

This reliance on fossil fuel has a direct impact on climate change as the burning of fossil fuels for energy not only releases toxic substances into the atmosphere but also leads to land degradation as more ores are extracted from the ground. The combustion of fossil fuels will increase anthropogenic conditions that will further exacerbate the issue of climate change and its consequences, i.e., food security [48]. This is because elevated levels of carbon dioxide can cause "protein content [in grain quality to decrease] by $10-14 \%$ in non-leguminous grain crops and concentrations of minerals, such as iron and zinc [to] decrease by 15-30\%" ([49], p. 109). Changes in food nutritional properties would in turn affect the quality of food being produced and hence the utilization of food. Hence, not only does food production and food processing contribute to GHG emissions that are detrimental to the environment but food miles also contribute to the increased concentration of atmospheric GHGs that worsen climate change.

Another factor of food production that affects climate change is the food we are producing. The increasing affluence of middle-class consumers and the rising urban population have led to changes in food preferences towards more meat-based diets. Global meat consumption has increased 325\% from 1961 to 2011 [50]. This increase in meat consumption is accompanied by increases in livestock-rearing producers and meat-based processing systems that seek to maximize profit through catering to the growing population's changing food preferences. However, the rise in global meat consumption has led to increased climate change effects, as it can take 10-20 times more energy and greenhouse gas emissions to produce certain meat-based foods than grains and vegetables [13].

According to the FAO [34], the livestock sector emits about "7.1 gigatonnes of carbon dioxide equivalent per year, representing 14.5 percent of all human-induced emissions". This significant amount of GHGs being emitted into the air has negative effects on climate change as it raises the global air temperature and affects the compositions of the atmosphere, which results in the increased occurrences of natural disasters. Thus, changing food consumption patterns play a significant role in influencing climate change.

In addition, land area required for livestock rearing is more significant than for crop producing. This is because "an area of $200 \mathrm{~m}^{2}$ can produce $142 \mathrm{~kg}$ of wheat or $9.6 \mathrm{~kg}$ of beef. The number of persons which can be fed in one day is 210 for the vegetarian diet and 13 for the beef diet" ([13], p. 14). It becomes clear that though both crop producing and livestock rearing requires the same amount of input $-200 \mathrm{~m}^{2}$ of land, the food outputs from crop producers are more substantial than for livestock rearing. However, changing consumption patterns favoring meat-based diets have created a market and need for producers to produce more poultry and this has resulted in more natural ecosystems being converted into agro-ecosystems.

Livestock rearing can also lead to soil erosion and desertification due to overgrazing. As mentioned earlier, the effects of soil erosion would affect the soil health which in turn affects the quality and quantity of produce and hence food security. In addition, soil erosion and desertification affects the soil carbon sequestration and reduces the soil's ability to remove atmospheric carbon dioxide that helps mitigate climate change. Carbon sequestration according to United Nations Convention to Combat Desertification (UNCCD) is "the process by which $\mathrm{CO}_{2}$ sinks (both natural and artificial) remove carbon dioxide from the atmosphere, primarily as plant organic matter in soils" ([51], p. 1). Soil plays an important role in mitigating climate change as after all, it holds more organic carbon than atmospheric $\mathrm{CO}_{2}$ and vegetation combined [50]. Poor soil health would thus affect the ability of soil to act as a sink to remove atmospheric carbon and thus results in higher levels of carbon dioxide concentration in the atmosphere, exacerbating climate change. 
Based on the examples highlighted above, it can be seen that food production systems have a direct/indirect influence on climate change. The increased release of anthropogenic gases into the atmosphere not only increases the concentration of GHGs but also increases the rate of warming in the atmosphere, as there are more GHGs to trap heat. In addition, food production can also affect food security as damage to the land through soil leaching, deforestation and salinization converts fertile, arable land into land that is unsuitable for crop production or livestock rearing.

\section{Conclusions}

In sum, food security, food production and climate change are all interlinked and intertwined. Changes in one factor would have negative impacts on the other factors. Take for example, the lack of food security. This would lead to the rise in food production, which would in turn lead to the worsening of climate change due to factors such as the clearing of land to support growing production systems. In addition, the energy used (burning of fossil fuels) and pollutants released during production processes might exacerbate the climate change issue. The three systems are intricately connected and hence changes to any system would have a domino effect on the other two systems.

The first thing that needs to be done is to kick-start substantial changes in one of the systems. It would probably be best not to change all the systems at the same time as this might result in chaos and confusion that might worsen the problems within each system. Solving the problem of the effects of food production systems that have increased global carbon footprints and exacerbated climate change, might be easier than the other two systems. This is because food production systems are managed and controlled by people. Changing production systems to adopt more environmentally-friendly production processes is easier compared to addressing climate change effects on food security that involves not only economic interests but also political interests.

With a projected increase of 2.4 billion people by 2050, it is vital that current food production systems should adopt an environmentally-friendly system so that Malthus' prophesy of geometric growth of population and arithmetic growth of food production leading to inevitable food insecurity does not come true. The wider adoption of environmentally-friendly food production systems would allow for sustainable development and progress for current and future generations to come and a higher chance of achieving both food security and better management of climate change. This is because with more environmentally-friendly food production systems and the introduction of environmental certification regimes, the current levels of GHG emissions can be reduced or maintained at levels where we are still able to seek solutions to mitigate and adapt to this phenomenon and address the problems in the other systems. The reduction of climate change effects will help to improve the food security problem as it reduces the likelihood of crop failure or the deaths of livestock due to natural disasters and climate change.

It is also important to note that the factors identified for causing climate change and the lack of food security in this report are limited and there remains a huge range of other factors that can or are contributing to climate change and threatening food security such as political instability and economic interests.

Acknowledgments: This research work was supported by a grant from the Nanyang Technological University Singapore, and the Ministry of Education Singapore. The authors thank the editors and the reviewers for their thoughtful comments and suggestions.

Author Contributions: Md Saidul Islam conceptualized and guided the entire project while Andrea Ting Wong collected materials and prepared the initial draft. Both authors then worked together to finalize the manuscript. Both authors claim equal authorship.

Conflicts of Interest: The authors declare no conflict of interest. 


\section{References}

1. The Straits Times. Obama Says World Must Speed up Climate Change Fight September 1. Available online: http:/ / www.straitstimes.com/world/united-states/obama-says-world-must-reach-climate-dealin-paris-while-we-still-can (accessed on 7 September 2015).

2. IPCC. Climate Change 2007: Synthesis Report. IPCC Fourth Assessment Report: Climate Change 2007. Available online: https://www.ipcc.ch/publications_and_data/ar4/syr/en/mains1.html (accessed on 27 August 2015).

3. Misra, A.K. Climate change and challenge of water and food security. Int. J. Sustain. Built Environ. 2014, 3, 153-165. [CrossRef]

4. Khandekar, N. Too Few Scientists Track Loss of Himalayan glaciers July 13. Available online: http://www. rtcc.org/2015/07/13/too-few-scientists-track-loss-of-himalayan-glaciers / (accessed 7 September 2015).

5. FAO. The State of Food Insecurity in the World 2015. Available online: http://www.fao.org/hunger/keymessages/en/ (accessed on 26 September 2015).

6. UNDESA. World Population Projected to Reach 9.7 Billion by 2050. Available online: https://www.un.org/ development/desa/en/news/population/2015-report.html (accessed on 11 December 2015).

7. FAO. The State of Food Insecurity in the World 2001. Available online: http://www.fao.org/docrep/003/ y1500e/y1500e00.htm (accessed on 26 September 2015).

8. BBC News. COP21 Climate Change Summit Reaches Deal in Paris. Available online: http://www.bbc.com/ news/science-environment-35084374 (accessed on 14 June 2016).

9. Uphoff, N.; Dazzo, F.B. Making Rice Production More Environmentally-Friendly. Environments 2016, 3, 12. [CrossRef]

10. FAO. Agriculture's Greenhouse Gas Emissions on the Rise. Available online: http://www.fao.org/news / story/en/item/216137/icode/ (accessed on 23 May 2016).

11. Thomas, V.; López, R. Global Increase in Climate-related Disasters November 2015. Available online: http:/ / www.adb.org/sites/default/files/publication/176899/ewp-466.pdf (accessed on 28 May 2016).

12. Gould, K.A.; Lewis, T.L. An Introduction to environmental sociology. In Twenty Lessons in Environmental Sociology, 1st ed.; Oxford University Press: New York, NY, USA, 2009; pp. 1-8.

13. Lal, R. Food Security in a Changing Climate. Echohydrol. Hydrobiol. 2013, 13, 8-21. [CrossRef]

14. Qafoku, N.P. Climate-change Effects on Soils: Accelerated Weathering, Soil Carbon and Elemental Cycling. Adv. Agron. 2015, 131, 111-172.

15. Islam, M.S. Development, Power and the Environment: Neoliberal Paradox in the Age of Vulnerability; Routledge: New York, NY, USA; London, UK, 2013.

16. Gschwendtner, S.; Tejedor, J.; Mueller, C.; Dannenmann, M.; Knabner, I.K.; Schloter, M. Climate Change Induces Shifts in Abundance and Activity Pattern of Bacteria and Archaea Catalyzing Major Transformation Steps in Nitrogen Turnover in a Soil from a Mid-European Beech Forest. PLoS ONE 2014, 9, e114278. [CrossRef] [PubMed]

17. St. Clair, S.B.; Lynch, J.P. The Opening of Pandora's Box: Climate change impacts on soil fertility and crop nutrition in developing countries. Plant Soil 2010, 335, 101-115. [CrossRef]

18. Shahid, S.A.; Ahmed, M. Environmental Cost and Face of Agriculture in the Gulf Cooperation Council Countries: Fostering Agriculture in the Context of Climate Change; Springer: Berlin, Germany, 2014; pp. 1-179.

19. UNDESA. Water Stress versus Water Scarcity. Available online: http://www.un.org/waterforlifedecade/ scarcity.shtml (accessed on 9 December 2015).

20. Kang, Y.; Khan, S.; Ma, X. Climate Change Impacts on crop Yield, Crop Water Productivity and Food Security-A Review. Prog. Nat. Sci. 2009, 19, 1665-1674. [CrossRef]

21. Feuchtmayr, H.; Moran, R.; Hatton, K.; Connor, L.; Heyes, T.; Moss, B.; Harvey, I.; Atkinson, D. Global warming and eutrophication: Effects on water chemistry and autotrophic communities in experimental hypertrophic shallow lake mesocosms. J. Appl. Ecol. 2009, 46, 713-723. [CrossRef]

22. Porter, J.R.; Xie, L.; Challinor, A.J.; Cochrane, K.; Howden, S.M.; Iqbal, M.M.; Travasso, M.I. Part A: Global and sectoral aspects. Contribution of working group II to the fifth assessment report of the intergovernmental panel on climate change. In Climate Change 2014: Impacts, Adaptation, and Vulnerability. Food security and food production systems; Cambridge University Press: Cambridge, UK; New York, NY, USA, 2014; pp. 485-533. 
23. Mahapatra, S. Impact of Climate Change on Indian Agriculture. In Climate Change Effect on Crop Productivity; Sengar, R.S., Sengar, K., Eds.; CRC Press: Boca Raton, FL, USA, 2014; pp. 213-228.

24. Baudron, A.R.; Needle, C.L.; Rijnsdorp, A.D.; Marshall, C.T. Warming Temperatures and Smaller Body Sizes: Synchronous Changes in Growth of North Sea Fishes. Glob. Chang. Biol. 2014, 20, 1023-1031. [CrossRef] [PubMed]

25. Cheung, W.W.L.; Brodeur, R.D.; Okey, T.A.; Pauly, D. Projecting future changes in distributions of pelagic fish species of Northeast Pacific shelf seas. Prog. Oceanogr. 2015, 130, 19-31. [CrossRef]

26. Kibria, G. Sea-Level-Rise and Its Impact on Wetlands, Agriculture, Fisheries, Aquaculture, Migration, Public Health, Infrastructure and Adaptation. Available online: https://www.researchgate.net/ publication/261216635_Climate_Change_and_Chemicals_Environmental_and_Biological_Aspects (accessed on 30 March 2017).

27. Farmar-Bowers, Q. Framing the Research Needs for Food Security in Australia. In Food Security in Australia: Challenges and Prospects for the Future; Farmar-Bowers, Q., Higgins, V., Millar, J., Eds.; Springer: New York, NY, USA, 2013; pp. 219-234.

28. Keating, A. Food Security in Australia: The Logistics of Vulnerability. In Food Security in Australia: Challenges and Prospects for the Future; Farmar-Bowers, Q., Higgins, V., Millar, J., Eds.; Springer: New York, NY, USA, 2013; pp. 21-34.

29. Santra, S.C.; Mallick, A.; Samal, A.C. Global Warming impact on Crop Productivity. In Climate Change Effect on Crop. Productivity; Sengar, R.S., Sengar, K., Eds.; CRC Press: Boca Raton, FL, USA, 2014; pp. 357-384.

30. Taub, D.R. Effects of Rising Atmospheric Concentrations of Carbon Dioxide on Plants. Nat. Educ. Knowl. 2010, 3, 21.

31. Shwartz, M. Climate Change Surprise: High Carbon Dioxide Levels Can Retard Plant Growth, Study Reveals. Available online: https:/ /news.stanford.edu/pr/02/jasperplots124.html (accessed on 10 June 2016).

32. Burke, M.; Lobell, D. Climate effects on food security: An overview. In Climate Change and Food Security: Adopting Agriculture to a Warmer World; Lobell, D., Burke, M., Eds.; Springer: Rotterdam, The Netherlands, 2010; pp. 13-30.

33. Úbeda, B.; Di Giacomo, A.S.; Neiff, J.J.; Loiselle, S.A.; Poi, A.S.G.; Gálvez, J.A.; Casco, S.; Cózar, A. Potential Effects of Climate Change on the Water Level, Flora and Macro-fauna of a Large Neotropical Wetland. PLOS ONE 2013, 8, e67787.

34. FAO. The Impact of Natural Hazards and Disasters on Agriculture and Food and Nutrition Security: A Call for Action to Build Resilient Livelihoods. Available online: http://www.fao.org/3/a-i4434e.pdf (accessed on 21 September 2015).

35. Singh, D.P. Global Warming impact on rice crop productivity. In Climate Change Effect on Crop Productivity; Sengar, R.S., Sengar, K., Eds.; CRC Press: Boca Raton, FL, USA, 2014; pp. 187-196.

36. IPCC. Food Security and Vulnerability. IPCC Fourth Assessment Report: Climate Change 2007. Available online: https://www.ipcc.ch/publications_and_data/ar4/wg2/en/ch5s5-6-5.html (accessed on 12 June 2016).

37. United States Consensus Bureau. World Population. Available online: http://www.census.gov/population/ international/data/worldpop/table_population.php (accessed on 28 September 2015).

38. Lal, R. Climate Change and Agriculture. Obs. Impacts Planet Earth 2016 2015, 2, 465-489.

39. Carlsson-Kanyama, A.; González, A.D. Potential Contributions of food consumption patterns to climate change 1-4. Am. J. Clin. Nutr. 2014, 89, 1704S-1709S. [CrossRef] [PubMed]

40. Watts, J. Brazil's Amazon Rangers Battle Farmers' Burning Business Logic 14 November. Available online: http:/ / www.theguardian.com/environment/2012/nov/14/brazil-amazon-rangers-farmers-burning (accessed on 28 September 2015).

41. Nowak, D.J. The Effects of Urban Trees on Air Quality. Available online: http://www.nrs.fs.fed.us/units / urban/local-resources/downloads/Tree_Air_Qual.pdf (accessed on 28 September 2015).

42. Lawrence, G.; Richards, C.; Burch, D. The Impacts of Climate Change on Australia's Food Production and Export. In Food Security in Australia: Challenges and Prospects for the Future; Farmar-Bowers, Q., Higgins, V., Millar, J., Eds.; Springer: New York, NY, USA, 2013; pp. 173-186.

43. Woods, J.; Williams, A.; Hughes, J.K.; Black, M.; Murphy, R. "Energy and the Food System". Philos. Trans. R. Soc. 2010, 365, 2991-3006. [CrossRef] [PubMed] 
44. Lin, B.B.; Chappell, M.J.; Vandermeer, J.; Smith, G.; Quintero, E.; Bezner-Kerr, R.; Griffith, D.M.; Ketcham, S.; Latta, S.C.; McMichael, P.; et al. Effects of Industrial Agriculture on Climate Change and the Mitigation Potential on Small-scale Agro-ecological Farms. CAB Rev. Perspect. Agric. Vet. Sci. Nutr. Nat. Resour. 2011, 6, 1-18. [CrossRef]

45. UNDESA. World Urbanization Prospects: The 2014 Revision. Available online: http://esa.un.org/unpd/ wup/FinalReport/WUP2014-Report.pdf (accessed on 11 December 2015).

46. The RSIS Centre for Non-Traditional (NTS) Studies. Food Security Expert Group Meeting on 'Food First: Ensuring food and Nutrition for Urbanites'. Available online: https://www.rsis.edu.sg/wp-content/ uploads/2014/07/ER100805_Food_First.pdf (accessed on 11 December 2015).

47. Wakeland, W.; Cholette, S.; Venkat, K. Chapter 9-Food Transportation Issues and Reducing Carbon Footprint. Green Technologies in Food Production and Processing. Available online: http://www. cleanmetrics.com/pages/Ch9_0923.pdf (accessed on 28 September 2015).

48. Adebisi-Adelani, O.; Oyesola, O.B. Adaptation Strategies of Citrus and Tomato Farmers towards the Effect of Climate Change in Nigeria. In Vulnerability of Agriculture, Water and Fisheries to Climate Change: Toward Sustainable Adaptation Strategies; Behnassi, M., Prasar, G.R.V., Shelat, K.N., Muteng'e, M.S., Eds.; Springer: Dordrecht, The Netherlands, 2014; pp. 157-166.

49. Ainsworth, E.A.; McGrath, J.M. Direct Effects of Rising Atmospheric Carbon Dioxide and Ozone on Crop Yields. In Climate Change and Food Security: Adopting Agriculture to a Warmer World; Lobell, D., Burke, M., Eds.; Springer: Rotterdam, The Netherlands, 2010; pp. 109-132.

50. National Geographic. What the World Eats. Available online: http://www.nationalgeographic.com/whatthe-world-eats / (accessed on 11 December 2015).

51. UNCCD. Climate Change and Desertification. Available online: http://www.unccd.int/Lists/ SiteDocumentLibrary/Publications/Desertificationandclimatechange.pdf (accessed on 11 December 2015).

(C) 2017 by the authors. Licensee MDPI, Basel, Switzerland. This article is an open access article distributed under the terms and conditions of the Creative Commons Attribution (CC BY) license (http://creativecommons.org/licenses/by/4.0/). 